\title{
Article \\ Goal-Setting among Biology Undergraduates during a Free-Choice Learning Experience at a Regional Zoo
}

\author{
Ashley B. Heim ${ }^{1,2, *(D)}$ and Emily A. Holt ${ }^{2}$ \\ 1 Department of Ecology and Evolutionary Biology, Cornell University, Ithaca, NY 14853, USA \\ 2 School of Biological Sciences, University of Northern Colorado, Greeley, CO 80639, USA; emily.holt@unco.edu \\ * Correspondence: abh229@cornell.edu
}

Citation: Heim, A.B.; Holt, E.A.

Goal-Setting among Biology

Undergraduates during a Free-Choice

Learning Experience at a Regional

Zoo. J. Zool. Bot. Gard. 2021, 2 ,

610-624. https://doi.org/10.3390/

jzbg2040044

Academic Editors: Michel Saint-Jalme and Sarah Spooner

Received: 29 September 2021

Accepted: 15 November 2021

Published: 18 November 2021

Publisher's Note: MDPI stays neutral with regard to jurisdictional claims in published maps and institutional affiliations.

Copyright: (c) 2021 by the authors. Licensee MDPI, Basel, Switzerland. This article is an open access article distributed under the terms and conditions of the Creative Commons Attribution (CC BY) license (https:/ / creativecommons.org/licenses/by/ $4.0 /)$.

\begin{abstract}
Free-choice learning occurs when individuals have autonomy in what and how they learn, and often takes place in informal settings such as zoos. To describe goal-setting and -achievement of biology undergraduates at a regional zoo, we primarily asked: (1) What types of learning goals do students set for themselves for a trip to the zoo?; and (2) What activities do students intend to engage in on a zoo trip? Participating students completed the first portion of a goal-setting assessment prior to entering the zoo, which asked students to develop learning and activity goals for themselves. At the conclusion of the zoo trip, students completed the second portion of this survey, which asked whether students achieved their goals, and if not, why. We found that most students devised learning goals related to gaining knowledge and identified passive interactions with animals as activities they hoped to engage in during their trip.
\end{abstract}

Keywords: goal-setting; free-choice learning; biology undergraduates; zoos; informal settings

\section{Introduction}

\subsection{What Is Free-Choice Learning in Informal Settings?}

Free-choice learning occurs when individuals have autonomy in what they would like to learn about, including the cognitive level at which they engage in this learning [1,2]. Falk et al. [2] define free-choice learning as a process in which the learner "is largely choosing what, how, where, and with whom to learn" (p. xix), and further differentiate this from the term "informal" by noting that the latter is used to describe institutional settings rather than types of learning. Such learning is also characterized by intrinsic motivationor an individual's engagement in an activity because he or she finds it rewarding and enjoyable [3]—and personal interest [4]. Thus, free-choice learning often, but not always, takes place in informal, out-of-school settings such as museums, science centers, zoos, and aquariums (MCZAs [5]).

Free-choice learning in MCZAs has been found to increase participants' understanding of science topics as well as improve their interest in the sciences [6-9], though the majority of this research has focused on students at the K-12 level. (In the U.S., Canada, and certain other countries, $\mathrm{K}-12$ refers to pre-college elementary and secondary school levels of education from kindergarten (K) through twelfth grade (12)). Limited research exists which explores free-choice learning among undergraduates or college-age adults.

\subsection{Intrinsic Motivation and Goal-Setting in Free-Choice Learning}

Blumenfeld and others [10] emphasized the relationship between personal motivation for a topic and an individual's ability to construct personal meaning within a potential learning situation. Prior studies have found that students were generally more committed to learning tasks in museums, and demonstrated greater persistence for learning when they are able to choose what exhibits they visited [11,12]. Falk and Storksdieck [13] noted that adult visitors to science centers tended to set motivational goals for themselves 
to better plan their experiences. Further, both $\mathrm{K}-12$ students [14] and undergraduate students [15] reportedly set learning goals for themselves in the formal classroom during more self-regulated or autonomy-supportive exercises that are more characteristic of freechoice learning experiences. However, the goals K-12 students set for themselves in informal settings are inherently different from those they set in the formal classroom. Further, students learning in an authentic, free-choice learning context are more likely to set and achieve learning goals that address their personal needs [11]. As Boekaerts and Minnaert [16] eloquently stated,

Self-regulation, in the true sense of the word, will only emerge when students are allowed to learn in a context where they can weigh the feasibility and desirability of alternative actions and goals, using their own criteria. The perception of freedom of action (an appraisal which informs students that they can act according to their own wishes, expectations and needs) in a supportive context (where they can borrow resources when needed) will help them to translate their own needs, expectations and wishes into clear intentions. (p. 542)

While the effects of individual students' achievement goals on their academic performance in formal settings has been studied, including how mastery of the content, competitiveness with peers, and initial interest in the subject matter influence such goals [17,18], little is known about undergraduate goal-setting during free-choice learning experiences, and tools or assessments to measure such behavior in informal settings do not currently exist. Dabbagh and Kitsantas [19] found that personal learning environments involving the use of social media platforms can help students' developmental self-regulation skills both formally and informally to attain their learning goals, though their study was not specific to informal settings such as zoos and aquariums.

\subsection{Theoretical Framework}

We founded our research on multiple theories. Broadly, we applied the Situated/Enacted Identity Framework (Falk, 2006; Rounds, 2006) to free-choice learning at the zoo in our study, as this framework was developed within the context of free-choice learning at informal settings. The Situated/Enacted Identity Framework focuses on visitor expectations, interest, and prior experiences within informal settings, and how these underlying factors may dynamically influence an individual's identity during a free-choice learning experience $[5,20,21]$. As our study focused on undergraduates' goal-setting during a zoo trip, we believed an individual's prior knowledge, interest, and expectations would highly impact what goals they developed at the start of the zoo trip.

We also relied on Ford's Taxonomy of Human Goals, and specifically the cognitive goals he described within this framework [22]. Ford [22] included four secondary goals within his broader category of cognitive goals: (1) exploration based on curiosity, (2) gaining knowledge, (3) engaging in creative thinking, and (4) maintaining a positive sense of self (e.g., self-confidence or self-worth). We used this cognitive goals framework to guide our primary research questions focused on students' learning goals at the zoo. Further, this framework has been used in the context of motivating students to learn via engagement in classroom activities [23].

Lastly, we utilized Engagement Theory [24,25] to describe students' activity-based goals (e.g., our second primary research question) during the zoo trip. Engagement Theory is founded on the idea that students engaged in meaningful learning, must be interacting with others and participating in purposeful tasks [24]. While this theory was not specifically formulated in the context of free-choice learning at informal settings, we believe it could apply to the activities students hoped to engage in during their zoo visits as it incorporates self-directed and experiential learning [24].

We opted to not rely on goal theory [26] or goal orientation theory $[27,28]$ in our framework. While these theories are relevant for relating goals and performance [26] and motivation and goal-setting [28], they are contextualized for the formal classroom with more traditional academic tasks. We did not believe these latter theories were as relevant 
in the context of free-choice learning in informal settings based on the types of goals we asked students to devise.

\subsection{Problem, Purpose, and Research Questions}

Considering the notable lack of persistence and waning interest in formal science education among undergraduates in the past several years [29], engaging more undergraduates in free-choice learning experiences could mitigate this leaky science, technology, engineering, and mathematics (STEM) pipeline. If free-choice learning in informal settings complements or fortifies what is learned in the classroom, a student may be more intrinsically motivated to learn about and value science in general [30]. Undergraduates, who have the opportunity to develop learning goals that cater more towards their own personal interests outside of the formal learning environment, may be more likely to engage in self-regulated learning and develop or maintain intrinsic motivation within the sciences. Thus, it is imperative to better understand how and why undergraduates set goals for themselves during free-choice learning experiences, and how achievement of those goals contributes to interest and persistence in biology.

The purpose of our current study-using a descriptive open-response survey focused on goal-setting - was to qualitatively describe what goals biology undergraduates set for themselves during a trip to a regional zoo, and to describe what types of goals students were able to fulfill during this learning opportunity. For students that did not achieve their individual goals, we also sought to discover what prevented them from doing so. Specifically, our primary research questions were:

1. What types of learning goals do students set for themselves at the zoo? What prevents them from accomplishing these learning goals?

2. What activities do students intend to engage in on their zoo trip, at what level of interaction do students intend to engage in activities during the zoo trip, and what prevents them from accomplishing these activity goals?

Secondarily, because learning in informal settings—specifically zoos-is often directly influenced by attitudes, emotions, and social interactions (e.g., [31-33]), we also sought to explore:

1. What attitudes or emotions do students intend to experience on their zoo trip?

2. What people do students intend to interact with on their zoo trip?

We intended these secondary research questions to support the primary research questions and theoretical framework described above, and thus are not discussed in as much depth.

\section{Materials and Methods}

\subsection{Ethics Statement}

The procedures for this study were approved by the Institutional Review Board of the University of Northern Colorado (IRB \#1301825-1). Written informed consent was obtained by all participating students at the beginning of the study.

\subsection{Participants and Zoo Trip}

We conducted our study at a public 4-year institution in the western U.S. within one introductory (i.e., organismal biology, $n=39$ ) and two advanced courses (i.e., animal behavior, $n=24$, and mammalogy, $n=15$ ) for biology majors. Alternative extra credit options were available to students who opted not to participate in our research. These three biology courses were taught in Fall 2018 by three different instructors. Our total response rate for pre- and post-assessments across all participants and courses was $78 \%$ ( $n=61$ out of 78 possible students), which is within the acceptable range for volunteer participation in psychological studies described by Baruch [34]. Nearly all participating students reported previously visiting a zoo at least once, including the zoo at which this study was conducted [35]. 
In our study, students in all three courses of interest visited an urban, regional zoo approximately 60 miles from the institution where this research was conducted. Free transportation and zoo admission were provided to each participant. All students were introduced to the offerings and features of this regional zoo-and received a map of all zoo exhibits-prior to completing the survey, so that all participants had sufficient knowledge to develop reasonable learning, activity, attitudinal/emotional, and social goals. For students in all courses except Mammalogy, the zoo trip was a course requirement. Additionally, each zoo trip lasted approximately seven hours, regardless of the day of the visit. Students were assigned to free-choice or structured learning groups, which dictated the level of autonomy during the visit, for a separate research study [36]. However, the lack of differences among these groups in previous work and preliminary analyses of the current data encouraged us to pool these learning groups in the current study, which contrasts with the differences Bamberger and Tal [37] noted across four groups of varying choice at a museum - though this could be due to different contexts, populations, and sample sizes between their study and our current findings. Further, all survey data across level (i.e., introductory and advanced) were combined in our thematic analyses, as similar coding patterns emerged across all students.

\subsection{Goal-Setting Assessment}

All students completed the open-response survey during their zoo trip. The survey is intended to serve as a descriptive survey to assess undergraduate goal-setting and visitor agenda development at a broad range of informal settings, such as zoos, rather than as a valid and reliable research instrument. The survey, which was developed by one of the authors in Fall 2018, includes five total pre-trip questions and nine total post-trip questions; ten questions are open-response, while four questions had a yes/no structure (Table 1). Questions denoted as (a) and (b) in Table 1 indicate secondary questions related to the primary questions, under which they are nested.

Table 1. Survey items. While students developed goals related to learning, activities, attitudes and emotions, and social groups, we report primarily on learning and activity goals (unshaded rows in table) in this manuscript. Pre- and post-survey questions are aligned in rows; for example, students answered Q1 at the start of the zoo trip and reflected on their Q1 response at the end of the zoo trip by answering Q5. Unshaded rows indicate our primary research questions, while shaded rows refer to our secondary research questions.

Pre-Zoo Trip Items

Post Zoo-Trip Items

Q5. Did you learn about the topic you originally hoped to learn about during your zoo trip?

Q1. What is one thing you hope to learn about on your zoo trip today? (Learning Goals)

Q2. What is something you hope to do on your zoo trip today? (Activity Goals)

Q3. What is one attitude/emotion you hope to experience on your zoo trip? (Attitude $\mathcal{E}$ Emotional Goals)

Q4. Who do you intend to interact with on your zoo trip today (e.g., friends, zoo staff/volunteers, faculty/GTAs, etc.)? (Social Goals)

Q4a. Why do you hope to interact with these people? (Social Goals)
Q5a. If yes, at which exhibit did you learn about this topic?

Q5b. If no, what prevented you from learning about this topic? Did failing to learn about this topic detract from your overall zoo experience?

Q6. Did you accomplish what you initially hoped to do on your zoo trip?

Q6a. If no, what prevented you from participating in/experiencing this behavior/activity? Did failing to participate in/experience this behavior/activity detract from your overall Denver Zoo experience?

Q7. Did you experience the attitude/emotion you originally wrote down during your zoo trip?

Q7a. If no, what prevented you from experiencing this attitude? Did failing to experience this attitude detract from your overall zoo experience?

Q8. Did you interact with the people you intended to interact with on the upcoming Denver Zoo trip (e.g., friends, zoo staff/volunteers, faculty/GTAs, etc.)?

Q8a. If no, what prevented you from interacting with these people? Did failing to interact with these people detract from your overall zoo experience? 
Once students arrived at the zoo-but prior to being admitted entry-each individual responded to the pre-zoo trip items on the survey, which inquired about specific goals they would like to accomplish (Table 1). At the conclusion of the zoo trip, students responded to the post-zoo trip items which inquired about whether students had accomplished their initial goals, and if not, why they did not accomplish those goals (Table 1). During this postzoo trip reflection, students still had access to their pre-zoo trip responses, as the survey was administered as a double-sided handout (i.e., with pre-trip questions on one side and post-trip questions on the reverse side). While students developed goals related to learning, activities, attitudes and emotions, and social groups, we will report primarily on learning and activity goals in this manuscript, but will also secondarily report on attitude/emotion and social goals (though student responses to these latter goals were more homogenous) (Table 1).

\subsection{Follow-Up Think-Aloud Interviews}

To provide insight into why students were setting learning and activity goals and why they were successful at achieving these goals (as one limitation of our post-trip questions was asking students to simply respond yes or no), we also conducted thinkaloud interviews [38] with a subset of 10 introductory biology students after participating in the zoo trip. During these short 20-30 min interviews, we asked participants "Why did you set this goal for your zoo trip?" for all pre-trip questions on the survey. We also asked participants "Did you accomplish this goal during your zoo trip? Why or why not?".

\subsection{Data Analyses}

We used basic descriptive statistics to calculate counts and percentages of student responses for survey items. As our study was based on qualitative methods, we used a thematic analysis approach to analyze students' responses on the survey. Students' written responses were transcribed and inductively coded into naturally emerging themes [39,40] guided by our framework using NVivo 12 software [41]. One researcher completed an initial coding of all raw open-response data from the learning and activity goal survey items through development of a preliminary codebook, and a second researcher checked this coding for consistency [42] so that both researchers could come to a final consensus on assigned themes with high intercoder agreement $(\alpha>0.90 ;$ [43]). The same process was also used to analyze participants' think-aloud interview responses.

\section{Results}

Overall, students cited a range of learning and activity goals for their visit to a regional zoo, and the majority of students reported accomplishing their individual goals. Most students cited a single learning goal and activity goal. The majority of students also reported positive attitudes and emotions they wanted to experience on the zoo trip, and listed similar groups of people they wanted to interact with; for these two questions on the survey, students tended to list two or more goals in their responses. Again, most students tended to accomplish their attitudinal/emotional and social goals. However, for students that did not accomplish their goals on the survey, many had similar reasons for why they were not able to do so. Here, we present the emergent themes we found for each research question, presented from most commonly cited to least. We should also note that activity goals from students could be dual-coded, though this did not occur frequently. In most cases of dual-coding, students cited more than one learning goal or activity goal. We end this section by reporting our findings from think-aloud interviews with a subset of students in which they articulated why they responded the way they did on the survey. While students' responses across our three participating courses were pooled in our analysis due to similar emergent themes, our think-aloud interviews suggested that students had diverse reasons for developing their learning and activity goals. 


\subsection{Student Learning Goals at the Zoo}

Students cited three of the four cognitive learning goals described by Ford [22] during their zoo trip: (1) exploration based on curiosity, (2) gaining knowledge, and (3) engaging in creative thinking. We did not identify any references related to Ford's [22] fourth cognitive goal of maintaining a positive sense of self, though this could be due to the fact that such goals would be difficult to interpret based on the open-response questions that we asked. Learning goal subnodes had mutual exclusivity; thus, no student reference could be coded into more than one learning goal. The number of students citing each learning goal in their survey responses are noted in Table 2.

Table 2. Emerging themes for Questions 1 and 2 on the survey, number of students citing each theme, and percent goal achievement for each theme. Learning goals were coded into mutually exclusive themes. Activity goal responses from students could be dual-coded into two or more themes, though this did not occur frequently. Additionally, one student cited that they were "open to learning anything" in their learning goal, which could not be categorized in one of the three learning goals themes.

\begin{tabular}{|c|c|c|c|}
\hline & & Total Students $(n=61)$ & Goal Achievement \\
\hline Item & & Learning Goals & \\
\hline \multirow{3}{*}{$\begin{array}{l}\text { Q1. What is one thing you hope to } \\
\text { learn about on your zoo trip today? } \\
\text { (Learning goals) }\end{array}$} & 1. Gaining knowledge & 41 & $85 \%$ \\
\hline & 2. Exploration based on curiosity & 17 & $100 \%$ \\
\hline & 3. Engaging in creative thinking & 2 & $50 \%$ \\
\hline \multirow{4}{*}{$\begin{array}{l}\text { Q2. What is something you hope to do } \\
\text { on your zoo trip today? (Activity goals) }\end{array}$} & \multicolumn{3}{|c|}{ Activity Goals } \\
\hline & 1. Passive interaction & 51 & $82 \%$ \\
\hline & 2. Unclear & 7 & $100 \%$ \\
\hline & 3. Direct interaction & 6 & $83 \%$ \\
\hline
\end{tabular}

\subsection{Gaining Knowledge}

We defined this learning goal as students who sought to gain knowledge or attain understanding about some topic or process, without explicitly mentioning their curiosity or emotions about the topic, or the personal relevance of the topic. Often, this included students who wanted to know more about a certain animal species or the behavior of a species. For example, one introductory student reported that he would like to learn more about "what penguins do in captivity", while an advanced student mentioned that she would like to "learn about non-rattlesnake venomous snakes".

\subsection{Exploration Based on Curiosity}

We defined this learning goal as students who sought to satisfy their curiosity about some topic or process and who explicitly mentioned their interest in the topic due to its novelty, their emotions about the topic, or its personal relevance in their lives. Often, this included students who wanted to learn more about human impacts on the zoo animals, animal well-being, and opportunities to discuss zoo-based careers with staff at the zoo. For example, one introductory student wanted to learn more about "how the [zookeepers] are working to make the animals as comfortable as possible", while one advanced student sought to learn about "possible pre-vet internship opportunities".

\subsection{Engaging in Creative Thinking}

We defined this learning goal as students who sought to utilize creative thinking during their zoo trip, or the process of "engaging in activities involving original thinking or novel or interesting ideas" ([22] p. 88). The two advanced student references included in this category cited novel ways of engaging in some process. While one mentioned he hoped to "learn about how to use new software when observing animal behavior", the 
other noted that he wanted to learn more about how to develop "real world ethograms [using] more wild, less domesticated animals". We believe these references best align with Ford's [22] critical thinking category because they were the only instances in which students reported thinking about phenomena related to animal behavior in novel ways beyond what they learned in the formal classroom; these students' responses suggested that they sought to answer behavioral questions using unique software or processes.

\subsection{What Prevents Students from Accomplishing Their Learning Goals?}

While students reported attaining their learning goals nearly $85 \%$ of the time, eight students did not. Six students cited external factors (i.e., factors beyond their individual control) in response to why they did not accomplish their original learning goals-including demonstrations being cancelled, exhibits being closed, and lack of zookeeper staff to answer questions. Four students cited internal factors (i.e., factors within their personal control) as reasons for not accomplishing their goals-including being interested in another animal exhibit and becoming distracted by the requirements of the assessment (in the structured group).

\subsection{Student Activity Goals and Levels of Interaction}

Students identified multiple activity goals for their zoo trip; we categorized all responses into one of two primary goals related to the level of interaction needed for students to engage in these activities. Overall, their activity goals required (1) their passive interaction, or (2) their direct interaction. We also included an unclear category for student responses that did not align with the two primary activity goals, but this category is not further discussed. The number of students citing each activity goal in their survey responses are noted in Table 2.

\subsection{Passive Interaction}

We defined these activity goals as those in which students might indirectly contact animals on their zoo trip; no activity goals described students indirectly interacting with people, so this goal solely focused on student passive interactions with animals. Some examples of these passive interactions included (a) watching, observing, and seeing animals $(n=40),(b)$ visiting exhibits or animals $(n=8)$, and (c) taking photos $(n=3)$.

\subsection{Direct Interaction}

We defined these activity goals as those in which students intended to engage in activities at the zoo via direct contact with animals or people. Thus, we had two primary sub-goals emerge during coding (i.e., direct interaction with animals, $n=5$, and direct interaction with people, $n=3$ ). First, students set activity goals to directly interact with animals by feeding $(n=3)$, and touching, holding, or petting $(n=3)$ them. Second, students hoped to directly interact with people (i.e., zoo employees and researchers) through talking $(n=2)$, and participating in a separate zoo-related research study on eye-tracking behavior $(n=1)$.

\subsection{What Prevents Students from Accomplishing Their Activity Goals?}

While students reported attaining their activity goals nearly $84 \%$ of the time, nine students did not. Six students cited external factors in response to why they did not accomplish their original activity goals, while three students cited internal factors as reasons for not accomplishing their goals; these external and internal factors were identical to those described above for learning goals.

\subsection{Student Attitudinal and Emotional Goals}

Students identified multiple attitudinal and emotional goals for their zoo trip; we categorized responses into one of two broad levels: positive and negative feelings (Table 3). While students tended to list multiple attitudes and emotions for this question, most responses $(n=69)$ were identified as positive feelings, while five were coded as neutral or 
unclear feelings (e.g., nostalgia, in which we could not decipher whether the student felt this was a positive or negative feeling), and four were coded as negative feelings. Among positive feelings, students frequently listed joy, interest and intellectual insight, excitement, and inspiration. All four of the negatively coded feelings were related to regret or unease at seeing animals in captivity; thus, the goal achievement for negative feelings reflects students reporting that they successfully avoided these feelings during the trip. While emotions and attitudes can be challenging to sort into coherent groups, we broadly used Roseman's [44] framework for proposed positive emotions to guide our coding process.

Table 3. Emerging themes for Questions 3 and 4 on the survey, number of students citing each theme, and percent goal achievement for each theme. Neither attitudinal/emotional goals nor social goals were coded into mutually exclusive themes, as both responses for both goal types could be dual-coded into two or more themes. Further, as the negative feelings coded for Q3 were intended to be avoided by students on their zoo trip, the "goal achievement" percent here represents how many students avoided the negative feelings they originally expressed on the pre-survey.

\begin{tabular}{|c|c|c|c|}
\hline & & Total Students $(n=61)$ & Goal Achievement \\
\hline Item & \multicolumn{3}{|c|}{ Attitudinal/Emotional Goals } \\
\hline \multirow{9}{*}{$\begin{array}{l}\text { Q3. What is one attitude/emotion you hope } \\
\text { to experience on your zoo trip? } \\
\text { (Attitudinal/emotional goals) }\end{array}$} & \multicolumn{3}{|c|}{ Positive feelings } \\
\hline & 1. Joy, contentment, amusement & 32 & $88 \%$ \\
\hline & 2. Interest and intellectual insight & 14 & $79 \%$ \\
\hline & 3. Excitement & 12 & $100 \%$ \\
\hline & 4. Inspiration, hope & 11 & $82 \%$ \\
\hline & \multicolumn{3}{|c|}{ Neutral/unclear feelings } \\
\hline & 5. Other feelings (e.g., nostalgia) & 5 & $60 \%$ \\
\hline & \multicolumn{3}{|c|}{ Negative feelings students wanted to avoid } \\
\hline & 6. Regret/unease at seeing animals in captivity & 4 & $50 \%$ \\
\hline \multirow{5}{*}{$\begin{array}{l}\text { Q4. Who do you intend to interact with on } \\
\text { your zoo trip today? (Social goals) }\end{array}$} & \multicolumn{3}{|c|}{ Social Goals } \\
\hline & 1. Peers/classmates & 47 & $89 \%$ \\
\hline & 2. Zoo staff & 30 & $90 \%$ \\
\hline & 3. Course instructors & 20 & $100 \%$ \\
\hline & 4. Other & 9 & $67 \%$ \\
\hline
\end{tabular}

\subsection{What Prevents Students from Accomplishing Their Attitudinal and Emotional Goals?}

While students reported attaining their positive feeling goals nearly $87 \%$ of the time and neutral/unclear feelings $60 \%$ of the time, those that did not cited a mixture of boredom, being overwhelmed by the amount of other visitors in the zoo, and simply experiencing alternate positive emotions as reasons for not accomplishing their initial goals. Further, two of the four students who reported negative feelings that they wanted to avoid during the zoo trip cited that they were able to avoid those feelings of regret/unease because they observed the zoo animals being cared for compassionately and safely. During the follow-up think-aloud interviews described below, one student explained their change of mindset:

"I'm always like hesitant about zoos, cause I know they make conservation efforts, kind of ... but they're still in captivity. And that's still sad. Like, I didn't really know about the conservation part, actually, until we went and they kind of talked about the conservation. And I remember one talk, they were talking about palm oil I believe, and how it ... was affecting different species. Yes ... they seem to be participating in advocating conservation of animals' natural environments".

\subsection{Student Social Goals}

Students reported three primary people they hoped to interact with on the zoo trip: peers/classmates $(n=47)$, zoo staff $(n=30)$, and course instructors $(n=20)$ (Table 3$)$. 
Students tended to list more than one social group they intended to interact with in their survey responses, and emergent themes were not aligned with a specific theoretical framework as we did for learning and activity goals since students' social goals were fairly homogeneous.

\subsection{What Prevents Students from Accomplishing Their Social Goals?}

While students reported attaining their social goals of interacting with peers, zoo staff, and instructors nearly $93 \%$ of the time, those that did not accomplish their initial social goals cited a combination contributing factors. Students mentioned that they engaged in alternate social interactions, or peers, zoo staff, and course instructors were less available to interact with than originally thought.

\subsection{Think-Aloud Interview Responses}

To provide insight into why students set the learning and activity goals they did, we conducted think-aloud interviews with a subset of 10 introductory biology students after participating in the zoo trip. All ten participants cited a personal interest in specific animals and animal behaviors as justification for why they developed their learning and activity goals (Table 4). A smaller portion of participants mentioned a desire to engage in novel, unique experiences, relevancy to class topics or other career interests, prior experiences, and expectations of signage or zoo staff to learn from as reasons for setting their learning and activity goals (Table 4). Representative quotes for each emergent theme are also presented in Table 4.

Table 4. Emerging themes from follow-up think-aloud interviews asking why students set their learning and activity goals, based on a subset of introductory biology students who participated in the zoo trip $(n=10)$. Participant's responses could be dual-coded into multiple categories.

\begin{tabular}{ccc}
\hline Emergent Themes & Total Number of References & Representative Quote \\
\hline $\begin{array}{c}\text { 1. Interest in specific animals and their } \\
\text { behaviors }\end{array}$ & 10 & $\begin{array}{c}\text { I wanted to see tigers, because I think they're super cool. And it's } \\
\text { one of the animals that like, really interests me. }\end{array}$ \\
\hline $\begin{array}{c}\text { 2. Desire to engage in novel, unique } \\
\text { experiences }\end{array}$ & 5 & $\begin{array}{c}\text { Zoos are pretty cool .. So it's pretty neat, looking at all these } \\
\text { animals that you don't actually get to see like on a regular basis }\end{array}$ \\
$\begin{array}{c}\text { 3. Relevancy to class topics or other career } \\
\text { interests }\end{array}$ & $\begin{array}{c}\text { I have an interest in biology. I don't have a huge interest in animals. } \\
\text { But I do know, animals relate a lot to humans, mammals are used in } \\
\text { studies quite often. I also really liked [the] monkeys, because there's } \\
\text { a lot of [medical] studies on monkeys and apes and stuff. }\end{array}$ & $\begin{array}{c}\text { I think gift shops are just fun because there's like, animals souvenirs } \\
\text { [and] I think maybe I had visited [this gift shop] when I was a kid. }\end{array}$ \\
\hline $\begin{array}{c}\text { 4. Prior experiences as a child/nostalgia } \\
\text { from }\end{array}$ & 2 & $\begin{array}{c}\text { I tend to [read off of signs] more than like, talk to people [when } \\
\text { visiting informal settings]. }\end{array}$ \\
\hline \begin{tabular}{l} 
5. Expectations of signage or zoo staff to learn \\
\hline
\end{tabular}
\end{tabular}

\section{Discussion}

\subsection{Students Most Often Set Learning Goals Related to Gaining Knowledge and Exploration Based on Curiosity}

We relied on Ford's Taxonomy of Human Goals, and specifically the cognitive goals he described within this framework [22], to describe students' learning goals on the survey. The majority of students cited learning goals related to gaining knowledge, while many also cited learning goals related to curiosity-based exploration. As two of the three participating courses required students to attend the zoo trip as part of the curriculum, it seems reasonable that many students developed learning goals to better understand various biology topics, which they may have simultaneously been learning about in their respective courses. Research at the K-12 level has found that exposing students to relevant course content prior to visiting an informal setting may prime students to better understand and learn scientific content during their visit $[4,45,46]$. Further, the informal nature of the zoo may have been sufficient to foster students' interest and motivation in learning, though the inevitable 
linkage of this trip to a course may have influenced the preponderance of learning goals related to furthering their understanding of biology topics and processes-further bridging the gap between formal and informal learning settings [47].

Nearly one-third of participating students also cited learning goals related to satisfying curiosity. As free-choice learning experiences in informal settings commonly induce curiosity among participants, it seems reasonable that students who may have been more familiar with the zoo's offerings also set more personally relevant, curiosity-driven activity goals [48]. Further, goal-setting in informal learning settings is driven by personal interest and relevance to the visitor-as learning in such places is not explicitly linked to the formal classroom [13]. Thus, students who cited more curiosity-based activity goals may have been more cognizant of what they personally wanted to gain from the zoo trip.

\subsection{Students Most Often Set Activity Goals Related to Passively Interacting with Animals at the Zoo}

Interestingly, we found that prior to the zoo trip, students generally developed more passive activity goals. Though others have found that interactive, hands-on field trips improve student attitudes and interests toward learning more so than passive field trips [49], we did not find this in our current study. The passivity associated with students' pre-zoo trip activity goals may have been due to a lack of knowledge regarding the specific regional zoo we visited in this study (e.g., students may not have researched what animal species were available at the zoo or what demonstrations were scheduled, despite receiving this information prior to the zoo trip). However, this expected passivity may have also been influenced by students' perceptions of informal settings as places of passive learning via observations and tours [50]. Students may not have been aware that more direct interactions with animals or zoo staff were possible. Based on Engagement Theory [24,25], the overwhelming frequency of passive rather than active interaction goals may suggest that many students were not participating in meaningful learning tasks, or were not aware that such activity opportunities existed at the zoo [24]. Free-choice learning at informal settings incorporates self-directed and experiential learning, which are also hallmarks of Engagement Theory [24]; thus, most students in our study may have intended to minimally engage in the zoo trip rather than fully immerse in a direct interaction.

However, others have found that opportunities to simply observe animals and visit their unique exhibits at zoos-what we define as "passive" interactions in our current study - can positively influence visitors' knowledge and attitudes regarding learning biology [51]. Students developed passive goals prior to the zoo trip based on activities they wanted to engage in, seemingly believing there would be enough self-direction during the trip to accomplish these behaviors [20]. As the novelty of the zoo environment may have been sufficient to enhance students' motivation and interest to learn biology and to allow most students to achieve their initial activity goals [52,53], students may not have considered the outcomes of passive versus direct interactions with animals; rather, they may have assumed that any interaction would improve their learning experience at the zoo through sensory and emotional aspects [54]. All zoo visitors will passively participate during their trip in some manner, whether through readings signs, watching animals, or observing demonstrations, but it is up to the individual to expand that engagement to include more direct interactions with animals and zoo staff $[55,56]$. Opportunities for direct engagement may be even more unclear for undergraduates, as this population generally makes few zoo trips annually $[35,36]$.

\subsection{Most Students Reported Achieving Their Learning and Activity Goals}

The majority of students achieved their learning and activity goals. One reason for such high goal accomplishment may have been that explicit goal-setting led to higher rates of motivation to accomplish goals during the zoo trip [57]. Alternatively, despite having scheduled time before and after the zoo trip to complete the survey, students may have developed goals that were "easier" to accomplish if they felt rushed. Further, students may also have devised simpler goals if they were unaware of learning and activity 
opportunities at the zoo, though all participants were presented with basic information and resources about the zoo prior to the trip. Future iterations of this research should ensure that students have ample time to develop their survey responses and that students have sufficient background knowledge of the zoo to generate meaningful goals.

\subsection{External and Internal Factors Prevented Students from Accomplishing Learning and Activity} Goals at the Zoo

While the majority of students achieved their original learning and activity goals during the zoo trip, several students cited that they were not able to do so-due to both external and internal reasons. The locus of control is a significant aspect of learning in zoos, as the level of self-control granted to an individual determines the amount of choice they have during a learning experience at an informal setting [58] compared to a formal classroom setting. Corno [59] emphasized the importance of controlling impulses and remaining on-task for visitors of informal settings, to improve the likelihood of achieving one's goals. This self-regulation may help to explain why some students that did not achieve their initial learning or activity goals still gained something from their zoo experience-while the goals of some of these students may have shifted during the zoo trip, they simply explored another aspect of the zoo they found interesting or engaging. Regarding goal-setting, external loci of control are more often linked to passivity, while internal loci of control are more frequently associated with greater self-efficacy [60]—or an individual's belief that they can accomplish a goal or perform some action successfully [61]. Thus, our participants that failed to accomplish their goals admitted that this failure did not detract from their overall zoo experience, likely because they tended to develop more passive goals that were often controlled more by external factors (e.g., exhibits were closed) rather than internal factors (e.g., lack of personal interest).

We believe it is also important to acknowledge that we only asked students to describe why they did not accomplish their goals (if applicable); future iterations of this goal-setting survey should also ask students why they were able to accomplish their goals, as this may have provided us insight into why the majority of students reported accomplishing their learning and activity goals. As students had to explain their responses if they noted that they did not accomplish their initial goals, this may have biased students to indicate that they did achieve their goals (i.e., answering "yes" rather than "no" on the survey).

4.5. Students Set Goals to Experience Positive Feelings and Social Interactions during Their Zoo Trip, and Most Achieve These Goals

While exploring students' attitudinal and emotional goals were secondary research questions in our study, our findings that students tend to set and achieve goals to experience positive feelings and engage in social interactions with peers, zoo staff, and instructors indeed support the idea that learning in informal settings can be influenced by emotions and sociality (e.g., [31-33]). However, we should emphasize that while it seems likely that students' learning, activity, emotional, and social goals interacted with each other in various ways, we did not test for these relationships in our analyses. That most students set goals to experience feelings like joy, interest, excitement, and inspiration suggests that zoos and other physical informal settings can indeed still engage college undergraduates in positive learning experiences, despite most prior literature focusing on college students learning in informal online and virtual environments (e.g., [62,63]). Further, students' achieved social interactions may be highly linked to meaningful learning and their activity goals, per Kearsley and Schneiderman's [24] Engagement Theory described as part of our theoretical framework above.

4.6. Students' Personal Interests in Specific Animals and Desire to Engage in Novel Experiences Influenced the Development of Their Learning and Activity Goals

All ten participants in our think-aloud interviews cited a personal interest in specific animals and animal behaviors as justification for why they developed their learning and activity goals (Table 4). Participants also frequently mentioned a desire to engage in novel, 
unique experiences and relevancy to class topics or other career interests (Table 4). While these responses represent only a subpopulation of the undergraduates who participated in the zoo trip and completed the survey, our findings show that various factors may drive students' goal-setting behaviors. As others have noted, interest, engagement, and motivation are key drivers of goal-setting among self-regulated learners, and often relate to achievement of learning goals [11]. In our current study, the idea that all ten participants reported personal interest in a specific animal or animal behavior at the zoo as a reason for setting their learning and activity goals suggests that physical informal settings indeed provide benefits beyond what the formal classroom can provide. That five participants also cited a desire to engage in novel, unique experiences as justification for why they developed their learning and activity goals further supports the concept that informal settings like zoos offer engaging, motivating, and autonomous learning experiences. Such positive learning experiences at informal settings can ultimately lead to persistence in STEM, as achievement of personal learning goals may encourage students to engage in additional informal learning opportunities based on their interests $[11,64]$.

\section{Conclusions, Implications, and Broader Impacts}

The purpose of our current study - using a descriptive survey focused on goal-settingwas to qualitatively describe what goals biology undergraduates set for themselves during a trip to a regional zoo, and to describe what types of goals students were able to fulfill during this learning opportunity. For students that did not achieve their individual goals, we also sought to discover what prevented them from doing so.

We found that most students identified learning goals related to gaining knowledge during their zoo trip and identified passive interactions with animals as activities they hoped to engage in during their trip. Students also reported goals of experiencing positive feelings and engaging in social interactions with peers, zoo staff, and course instructors. Further, we concluded that goal achievement was high across all students. Students cited a range of external and internal factors that prevented them from accomplishing learning and activity goals at the zoo, though again, this encompassed a minority of participating students. Additionally, based on think-aloud interviews with a subset of students who participated in the zoo trip, we found that students' personal interests in specific animals and desire to engage in novel experiences influenced the development of their learning and activity goals.

We suggest that undergraduates who have the opportunity to develop learning and activity goals that better align with their intrinsic interests may be more likely to engage in self-regulated learning and develop or maintain intrinsic motivation within the sciences, which could ultimately lead to improved retention of undergraduates in science college programs. As limited research has been conducted on this topic, we sought to establish a baseline for goal-setting behaviors among biology undergraduates in informal settings, which future studies can use as starting point for exploring more specific aspects of goalsetting in places like zoos. It is imperative that we continue to research how and why undergraduates set goals for themselves during free-choice learning experiences-across diverse informal settings, demographics such as race, gender, and first-generation status, and a broad range of institutions and STEM courses-and how achievement of these goals contributes to their interest and persistence in biology.

Future studies should explore how effective informal learning experiences truly are at supporting learning in the formal classroom, as we still have a limited understanding of how visits to informal settings influence students' long-term STEM learning [65,66]. Morris et al. [11] also recommend that out-of-school learning supports are needed to make science content more relevant and interesting, and to improve the effectiveness of learning beyond the formal classroom. While most prior studies in informal learning have been conducted at the K-12 level, high attrition rates of undergraduates in biology and other STEM programs warrant both quantitative (e.g., concept inventories) and qualitative (e.g., 
interviews) methodologies to expand our knowledge of how informal settings contribute to college students' interest and persistence in STEM.

Author Contributions: Conceptualization, A.B.H. and E.A.H.; methodology, A.B.H. and E.A.H.; software, A.B.H.; validation, A.B.H. and E.A.H.; formal analysis, A.B.H.; investigation, A.B.H. and E.A.H.; resources, A.B.H.; data curation, A.B.H.; writing—original draft preparation, A.B.H.; writingreview and editing, A.B.H. and E.A.H.; visualization, A.B.H. and E.A.H.; supervision, E.A.H.; project administration, A.B.H.; funding acquisition, N/A. All authors have read and agreed to the published version of the manuscript.

Funding: This research received no external funding.

Institutional Review Board Statement: The study was approved by the Institutional Review Board of the University of Northern Colorado (protocol code \#1301825-1 in Fall 2018).

Informed Consent Statement: The procedures for this study were approved by the Institutional Review Board of the University of Northern Colorado (IRB \#1301825-1). Written informed consent was obtained by all participating students at the beginning of the study.

Data Availability Statement: To protect the privacy and confidentiality of the human research subjects used in this study (i.e., students), and in accordance with University of Northern Colorado IRB regulations, data can be obtained by contacting the first author at abh229@cornell.edu. Upon written request, we can release data as de-identified and in aggregate form. For more information about this restriction, please contact Nicole Morse, UNC Research Compliance Manager (Nicole.morse@unco.edu).

Acknowledgments: We thank all of the instructors and students who participated in our study.

Conflicts of Interest: The authors declare no conflict of interest.

\section{References}

1. National Research Council (NRC). Learning Science in Informal Environments; National Academies Press: Washington, DC, USA, 1996.

2. Falk, J.H.; Dierking, L.D.; Foutz, S. In Principle, in Practice: Museums as Learning Institutions; Rowman Altamira: Lanham, MD, USA, 2007.

3. Sansone, C.; Harackiewicz, J.M. (Eds.) Intrinsic and Extrinsic Motivation: The Search for Optimal Motivation and Performance; Elsevier: Amsterdam, The Netherlands, 2000.

4. Falk, J.H.; Dierking, L.D. Learning from Museums: Visitor Experiences and the Making of Meaning; AltaMira Press: Walnut Creek, CA, USA, 2000.

5. National Research Council (NRC). Learning Science in Informal Environments; National Academies Press: Washington, DC, USA, 2009.

6. Adams, J.D.; Branco, B. Extending classrooms into parks through informal science learning and place-based education. In Preparing Informal Science Educators; Patrick, P., Ed.; Springer: New York, NY, USA, 2017; pp. 337-354.

7. Drissner, J.R.; Haase, H.M.; Wittig, S.; Hille, K. Short-term environmental education: Long-term effectiveness? J. Biol. Educ. 2014, 48, 9-15. [CrossRef]

8. Schwan, S.; Grajal, A.; Lewalter, D. Understanding and engagement in places of science experience: Science museums, science centers, zoos, and aquariums. Educ. Psychol. 2014, 49, 70-85. [CrossRef]

9. Zimmerman, H.T.; McClain, L.R. Family learning outdoors: Guided participation on a nature walk. J. Res. Sci. Teach. 2015, 53, 919-942. [CrossRef]

10. Blumenfeld, P.C.; Soloway, E.; Marx, R.W.; Krajcik, J.S.; Guzdial, M.; Palincsar, A. Motivating project-based learning: Sustaining the doing, supporting the learning. Educ. Psychol. 1991, 26, 369-398.

11. Morris, B.J.; Owens, W.; Ellenbogen, K.; Erduran, S.; Dunlosky, J. Measuring informal STEM learning supports across contexts and time. Int. J. STEM Educ. 2019, 6, 40. [CrossRef]

12. Mujtaba, T.; Lawrence, M.; Oliver, M.; Reiss, M.J. Learning and engagement through natural history museums. Stud. Sci. Educ. 2018, 54, 41-67. [CrossRef] [PubMed]

13. Falk, J.H.; Storksdieck, M. Science learning in a leisure setting. J. Res. Sci. Teach. 2010, 47, 194-212. [CrossRef]

14. Eckes, A.; Großmann, N.; Wilde, M. Studies on the effects of structure in the context of autonomy-supportive or controlling teacher behavior on students' intrinsic motivation. Learn. Individ. Differ. 2018, 62, 69-78. [CrossRef]

15. Kitsantas, A.; Dabbagh, N. The role of Web 2.0 technologies in self-regulated learning. New Dir. Teach. Learn. 2011, 2011, 99-106. [CrossRef]

16. Boekaerts, M.; Minnaert, A. Self-regulation with respect to informal learning. Int. J. Educ. Res. 1999, 31, 533-544. [CrossRef] 
17. Harackiewicz, J.M.; Durik, A.M.; Barron, K.E.; Linnenbrink-Garcia, L.; Tauer, J.M. The role of achievement goals in the development of interest: Reciprocal relations between achievement goals, interest, and performance. J. Educ. Psychol. 2008, 100, 105-122. [CrossRef]

18. Pintrich, P.R. Multiple goals, multiple pathways: The role of goal orientation in learning and achievement. J. Educ. Psychol. 2000, 92, 544. [CrossRef]

19. Dabbagh, N.; Kitsantas, A. Personal learning environments, social media, and self-regulated learning: A natural formula for connecting formal and informal learning. Internet High. Educ. 2012, 15, 3-8. [CrossRef]

20. Falk, J.H. An identity-centered approach to understanding museum learning. Curator Mus. J. 2006, 49, 151-166. [CrossRef]

21. Rounds, J. Doing identity work in museums. Curator Mus. J. 2006, 49, 133-150. [CrossRef]

22. Ford, M.E. Motivating Humans: Goals, Emotions, and Personal Agency Beliefs; Sage Publications: Thousand Oaks, CA, USA, 1992.

23. Wentzel, K.R.; Brophy, J.E. Motivating Students to Learn; Routledge: Abingdon, UK, 2014.

24. Kearsley, G.; Shneiderman, B. Engagement theory: A framework for technology-based teaching and learning. Educ. Technol. 1998, $38,20-23$.

25. Schneiderman, B.; Alavi, M.; Norman, K.; Borkowski, E.Y. Windows of opportunity in electronic classrooms. Commun. ACM 1995, 38, 19-24. [CrossRef]

26. Locke, E.A.; Latham, G.P. Building a practically useful theory of goal setting and task motivation: A 35-year odyssey. Am. Psychol. 2002, 57, 705-717. [CrossRef]

27. Dweck, C.S. Motivational processes affecting learning. Am. Psychol. 1986, 41, 1040. [CrossRef]

28. Kaplan, A.; Maehr, M.L. The contributions and prospects of goal orientation theory. Educ. Psychol. Rev. 2007, 19, 141-184. [CrossRef]

29. Chen, X.; Soldner, M. STEM Attrition: College Students' Paths into and out of STEM Fields; National Center for Educational Statistics, U.S. Department of Education: Washington, DC, USA, 2013.

30. Pugh, K.J.; Phillips, M.M. Helping students develop an appreciation for school content. Theory Into Pract. 2011, 50, 285-292. [CrossRef]

31. Luebke, J.F.; Watters, J.V.; Packer, J.; Miller, L.J.; Powell, D.M. Zoo visitors' affective responses to observing animal behaviors. Visit. Stud. 2016, 19, 60-76. [CrossRef]

32. Perdue, B.M.; Stoinski, T.S.; Maple, T.L. Using technology to educate zoo visitors about conservation. Visit. Stud. 2012, 15, 16-27. [CrossRef]

33. Randler, C.; Baumgärtner, S.; Eisele, H.; Kienzle, W. Learning at workstations in the zoo: A controlled evaluation of cognitive and affective outcomes. Visit. Stud. 2007, 10, 205-216. [CrossRef]

34. Baruch, Y. Response rate in academic studies-A comparative analysis. Hum. Relat. 1999, 52, 421-438. [CrossRef]

35. Heim, A.B.; Holt, E.A. Describing informal learning experiences among college-age adults. J. STEM Outreach 2021, 4, 1-10. [CrossRef]

36. Heim, A.B.; Holt, E.A. Undergraduates' motivation following a zoo experience: Status matters but structure does not. J. Exp. Educ. 2021, 10538259211012716. [CrossRef]

37. Bamberger, Y.; Tal, T. Learning in a personal context: Levels of choice in a free choice learning environment in science and natural history museums. Sci. Educ. 2007, 91, 75-95. [CrossRef]

38. Adams, W.K.; Wieman, C.E. Development and validation of instruments to measure learning of expert-like thinking. Int. J. Sci. Educ. 2011, 33, 1289-1312. [CrossRef]

39. Aronson, J. A pragmatic view of thematic analysis. Qual. Rep. 1994, 2, 1-3. [CrossRef]

40. Bogdan, R.; Taylor, S.J. Relationships with severely disabled people: The social construction of humanness. Soc. Probl. 1989, 36, 135-148. [CrossRef]

41. QSR International. NVivo 12; QSR International: Doncaster, VIC, Australia, 2018.

42. Thomas, D.R. A general inductive approach for analyzing qualitative evaluation data. Am. J. Eval. 2006, 27, 237-246. [CrossRef]

43. Creswell, J.W. Qualitative Inquiry and Research Design: Choosing Among Five Approaches; Sage: Thousand Oaks, CA, USA, 2013.

44. Roseman, I.J. Comment: Frameworks for theory and research on positive emotions. Emot. Rev. 2017, 9, 238-244. [CrossRef]

45. Gennaro, E.D. The effectiveness of using previsit instructional materials on learning for a museum field trip experience. J. Res. Sci. Teach. 1981, 18, 275-279. [CrossRef]

46. Stoneberg, S.A. The Effects of Pre-Visit, On-Site, and Post-visit Zoo Activities Upon the Cognitive Achievement and Attitudes of Sixth Grade Pupils; University of Minnesota: Minneapolis, MN, USA, 1981; Volume 1.

47. Dierking, L.D. A view through another window: Free-choice science learning and generation R. In Assessing Schools for Generation $R$ (Responsibility); Springer: New York, NY, USA, 2014; pp. 307-319.

48. Koran, J.J.; Koran, M.L.; Foster, J.S. Individual differences in learning in informal settings. In Proceedings of the First Annual Visitor Studies Conference; Center for Social Design: Jacksonville, FL, USA, 1988; Volume 1, pp. 66-72.

49. Koran, J.J.J.; Baker, S.D. Evaluating the effectiveness of field experiences. In What Research Says to the Science Teacher; Rowe, M.B., Ed.; National Science Teachers Association: Washington, DC, USA, 1979; Volume 2, pp. 50-67.

50. Rennie, L.; McClafferty, T. Using visits to interactive science and technology centers, museums, aquaria, and zoos to promote learning in science. J. Sci. Teach. Educ. 1995, 6, 175-185. [CrossRef] 
51. Ballantyne, R.; Packer, J.; Falk, J. Visitors' learning for environmental sustainability: Testing short-and long-term impacts of wildlife tourism experiences using structural equation modelling. Tour. Manag. 2011, 32, 1243-1252. [CrossRef]

52. Black, A.E.; Deci, E.L. The effects of instructors' autonomy support and students' autonomous motivation on learning organic chemistry: A self-determination theory perspective. Sci. Educ. 2000, 84, 740-756. [CrossRef]

53. Myers, O.E., Jr.; Saunders, C.D.; Birjulin, A.A. Emotional dimensions of watching zoo animals: An experience sampling study building on insights from psychology. Curator Mus. J. 2004, 47, 299-321. [CrossRef]

54. Wünschmann, S.; Wüst-Ackermann, P.; Randler, C.; Vollmer, C.; Itzek-Greulich, H. Learning achievement and motivation in an out-of-school setting-Visiting amphibians and reptiles in a zoo is more effective than a lesson at school. Res. Sci. Educ. 2017, 47, 497-518. [CrossRef]

55. Anderson, U.S.; Kelling, A.S.; Pressley-Keough, R.; Bloomsmith, M.A.; Maple, T.L. Enhancing the zoo visitor's experience by public animal training and oral interpretation at an otter exhibit. Environ. Behav. 2017, 35, 826-841. [CrossRef]

56. Povey, D.D.; Rios, J. Using interpretive animals to deliver affective messages in zoos. J. Interpret. Res. 2002, 7, 19-28. [CrossRef]

57. Locke, E.A. Motivation through conscious goal setting. Appl. Prev. Psychol. 1996, 5, 117-124. [CrossRef]

58. Paris, S.G. Situated motivation and informal learning. J. Mus. Educ. 1997, 22, 22-27. [CrossRef]

59. Corno, L. Self-regulated learning: A volitional analysis. In Self-Regulated Learning and Academic Achievement; Springer: New York, NY, USA, 1989; pp. 111-141.

60. Phillips, J.M.; Gully, S.M. Role of goal orientation, ability, need for achievement, and locus of control in the self-efficacy and goal-setting process. J. Appl. Psychol. 1997, 82, 792. [CrossRef]

61. Lawson, A.E.; Banks, D.L.; Logvin, M. Self-efficacy, reasoning ability, and achievement in college biology. J. Res. Sci. Teach. Off. J. Natl. Assoc. Res. Sci. Teach. 2007, 44, 706-724. [CrossRef]

62. Cain, J.; Policastri, A. Using Facebook as an informal learning environment. Am. J. Pharm. Educ. 2011, 75, 207. [CrossRef] [PubMed]

63. Poitras, E.G.; Harley, J.M.; Compeau, T.; Kee, K.; Lajoie, S.P. Augmented reality in informal learning settings: Leveraging technology for the love of history. In Handbook of Research on Serious Games for Educational Applications; IGI Global: Hershey, PA, USA, 2017; pp. 272-293.

64. Eberbach, C.; Crowley, K. From everyday to scientific observation: How children learn to observe the biologist's world. Rev. Educ. Res. 2009, 79, 39-68. [CrossRef]

65. Dorph, R.; Schunn, C.D.; Crowley, K. Crumpled molecules and edible plastic: Science learning activation in out-of-school time. Afterschool Matters 2017, 25, 18-28.

66. Thoman, D.B.; Sansone, C.; Geerling, D. The dynamic nature of interest: Embedding interest within self-regulation. In The Science of Interest; Springer: Cham, Switzerland, 2017; pp. 27-47. 